\title{
CONTRIBUIÇÃO DOS MECANISMOS DE FLUXO DE MASSA E DE DIFUSÃO PARA O SUPRIMENTO DE K, Ca E Mg A PLANTAS DE ARROZ(1)
}

\author{
H. A. RUIZ ${ }^{(2)}$, J . MIRANDA ${ }^{(3)} \&$ J . C. S. CONCEIÇÃO ${ }^{(4)}$
}

\begin{abstract}
RESUMO
0 transporte de nutriente até à superfície das raízes pode ocorrer por fluxo de massa ou por fluxo de massa e difusão, dependendo da atividade do nutriente na solução do solo e da exigência nutricional da planta. Objetivou-se verificar a contribuição dos mecanismos de fluxo de massa e de difusão para o suprimento de potássio, de cálcio e de magnésio a plantas de arroz, em experimento realizado em casa de vegetação. Aplicaram-se em amostra de Latossolo Variação Una, os seguintes tratamentos: $\mathrm{Na}_{2} \mathrm{CO}_{3}, \mathrm{~K}_{2} \mathrm{CO}_{3}, \mathrm{CaCO}_{3}$ e MgCO 3 . Aos 75 dias da semeadura, as plantas de arroz foram colhidas e determinadas as quantidades de potássio, de cálcio e de magnésio nelas acumuladas, bem como a concentração desses nutrientes na solução do solo. Essas concentrações, multiplicadas pelo volume de água transpi rado, foram usadas para calcular o suprimento por fluxo de massa. A difusão foi estimada por diferença entre a quantidade do nutriente acumulado no vegetal e a transportada por fluxo de massa. Verificou-se que o potássio foi transportado predomi nantemente por difusão, exceto no tratamento com $\mathrm{K}_{2} \mathrm{CO}_{3}$, que gerou altos teores de $\mathrm{K}$ na solução de solo, tornando o fluxo de massa suficiente para atender à demanda das plantas. $O$ cálcio e o magnésio foram transportados por fluxo de massa. Segundo os resultados, a difusão foi o principal mecanismo de transporte de potássio nas condições do experimento; todavia, o fluxo de massa pode satisfazer isoladamente a demanda nutricional da planta, quando a concentração de potássio na solução do solo for muito elevada.
\end{abstract}

Termos de indexação: macronutrientes catiônicos, transporte, Oryza sativa.

\footnotetext{
(1) Recebido para publicação em maio de 1997 e aprovado em junho de 1999.

(2) Professor do Departamento de Sol os, Universidade Federal de Viçosa. CEP 36571-000 Viçosa (MG). Bolsista do CNPq.

(3) Engenheiro-Agrônomo do Ministério da Agricultura e Abastecimento. CEP 36571-000 Viçosa (MG).

(4) Pós-graduando em Engenharia Agronômica, Universidade de Brasília. CEP 70910-900 Brasília (DF). Bolsista do CNPq.
} 


\title{
SUMMARY: CONTRIBUTION OF MASS FLOW AND DIFFUSION MECHANISMS FOR SUPPLYING K, Ca AND Mg TO RICE PLANTS
}

\begin{abstract}
Nutrient transport towards root surfacecan be accomplished by mass flow or by mass flow and diffusion, depending on the activity of thenutrient in the soil sol ution, and on the nutrient demand of the plant. The objective of this greenhouse experiment was to verify the contribution of themechanisms of mass flow and diffusi on for supplying potassium, calcium and magnesium to riceplants. Samples of a clayey Oxysol weretreated with $\mathrm{Na}_{2} \mathrm{CO}_{3}, \mathrm{~K}_{2} \mathrm{CO}_{3}$, $\mathrm{CaCO}_{3}$ and $\mathrm{MgCO}_{3}$ as amendments. Seventy-five days after planting, the amounts of dry matter, potassium, calcium and magnesium accumulated were determined. Soil solution concentration of thesenutrients was also analyzed and used with theamount of transpired water to cal culatemass flow. Diffusion was cal culated by subtracting mass fl ow contri buti on from total nutrient plant accumulation. Potassium was transported predominantly by diffusion, except where $\mathrm{K}_{2} \mathrm{CO}_{3}$ was used, which yiel ded high soil solution $\mathrm{K}$ concentration and supplied enough potassi um to the plants through mass flow. Cal cium and magnesium were transported by mass flow. It is concluded that diffusion of potassium was the main mechanism of potassium transport but mass flow might solely supply plant demand when the concentration of potassium in the soil solution is very high.
\end{abstract}

Index terms: cationic macronutrients, transport, Oryza sativa.

\section{NTRODUÇÃO}

Os íons presentes na solução do solo são transportados às raízes das plantas por fluxo de massa ou por fluxo de massa e difusão. O fluxo de massa está associado ao gradiente de potencial total que regula o movimento da água no sistema soloplanta-atmosfera. Assim, a concentração do íon na solução do solo e a taxa de transpiração do vegetal determinam a quantidade de íons transportada por meio desse mecanismo (Barber, 1974). A difusão é devida ao movimento térmico e aleatório dos íons ou moléculas em meio líquido. O gradiente de concentração provoca um movimento maior de íons na direção dos pontos de absorção do que em sentido oposto (Wild, 1981). O mecanismo de interceptação radicular não é considerado no transporte de nutrientes, pois, atualmente, não é aceita a possibilidade de trocas diretas entre as partículas do sol o e as raízes das plantas, havendo necessidade do meio líquido para que a absorção pelas raízes ocorra.

Dentre os macronutrientes catiônicos, o cálcio e o magnésio são transportados por fluxo de massa, enquanto o potássio, fundamental mente, por difusão (Barber, 1974). Comparando o cálcio e o potássio, Ruiz (1986) sugeriu que, considerando outras características semelhantes, a tendência ao transporte por difusão de um cátion na solução do solo seria maior quanto maior a interação cátioncolóide. Para verificar a importância relativa dessa interação no transporte dos dois el ementos, considerou-se a força de atração coulômbica entre as partículas de carga elétrica oposta. Admitindo ser a densidade de carga elétrica negativa dos minerais da fração argila a mesma e usando os valores da valência e do raio iônico hidratado $(0,228 \mathrm{~nm}$ para o $\mathrm{Ca}^{2}+$ e $0,232 \mathrm{~nm}$ para o $\mathrm{K}+($ Cotton \& Wilkinson, 1966)), observa-seque a força de atração cál cio-argila é 2,071 vezes maior do que a força de atração potássio-argila. I sso levaria a uma menor liberação de cálcioà solução do solo sea concentração de ambos fosse igual na fase sólida do solo.

Considerando os coeficientes de difusão em uma solução pura $\left(0,8 \times 10^{-5} \mathrm{~cm}^{2} \mathrm{~s}^{-1}\right.$ para o $\mathrm{Ca}^{2+} \mathrm{e} 2,0 \mathrm{x}$ $10^{-5} \mathrm{~cm}^{2} \mathrm{~s}^{-1}$ para o $\left.\mathrm{K}+\right)$, o potássio apresenta um val or 2,5 vezes superior ao do cálcio. A maior força de atração cátion-colóide e o menor coeficiente de difusão na solução levariam à conclusão de que o mecanismo de difusão seria mais importante para o cálcio do que para o potássio.

Essa aparente discrepância entre os resultados experimentais e as considerações teóricas seria justificada pela relação de concentrações, entre o cálcio e o potássio, no complexo de troca catiônico (Ruiz, 1986). Normalmente, a concentração do cálcio é superior à do potássio, apresentando relações da ordem de 10 a 20 vezes. Tal diferença reflete-se na atividade desses cátions na solução do solo, o que explicaria o transporte de cálcio por fluxo de massa e o do potássio por difusão.

Estetrabal ho objetivou quantificar a contribuição dos mecanismos de fluxo de massa e de difusão no suprimento de K, Ca e Mg a plantas de arroz, utilizando amostras de um solo ao qual foram aplicados $\mathrm{Na}_{2} \mathrm{CO}_{3}, \mathrm{~K}_{2} \mathrm{CO}_{3}, \mathrm{CaCO}_{3}$ e $\mathrm{MgCO}_{3}$. 


\section{MATE RIAL E MÉTODOS}

O ensaio foi realizado em casa de vegetação, utilizando amostras de um Latossolo Variação Una proveniente de Viçosa, MG, com as seguintes

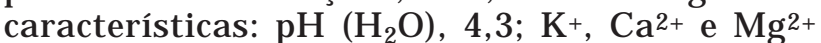
trocáveis, respectivamente, $0,069,0,2 \mathrm{e} 0,1 \mathrm{cmol}_{\mathrm{c}} \mathrm{dm}^{-3}$; eargila, 0,55 kg kg-3 (EMBRAPA, 1979).

Os tratamentos corresponderam à aplicação de um dos quatro sais $\left(\mathrm{Na}_{2} \mathrm{CO}_{3}, \mathrm{~K}_{2} \mathrm{CO}_{3}, \mathrm{CaCO}_{3}\right.$ ou $\mathrm{MgCO}_{3}$ ) em doses suficientes para elevar o pH até 6. Essas doses, determinadas previamente por meio de curvas de incubação, foram de 1,32, 2,25, 2,68 e $2,09 \mathrm{~g} \mathrm{dm}^{-3}$, para $\mathrm{Na}_{2} \mathrm{CO}_{3}, \mathrm{~K}_{2} \mathrm{CO}_{3}, \mathrm{CaCO}_{3} \mathrm{eM} \mathrm{gCO}_{3}$, respectivamente. Após a adição de $68,150,4$ e $1,3 \mathrm{mg} \mathrm{dm}-3$, respectivamente, de $\mathrm{N}, \mathrm{P}, \mathrm{Zn}$ e Cu, as amostras de sol o foram incubadas por 30 dias, com umidade próxima à capacidade decampo $\left(0,32 \mathrm{~kg} \mathrm{~kg}^{-1}\right)$. Os valores médios de $\mathrm{pH}$, determinados após a incubação, foram de 6,1, 5,9, 5,8 e 5,8, para $\mathrm{Na}_{2} \mathrm{CO}_{3}$, $\mathrm{K}_{2} \mathrm{CO}_{3}, \mathrm{CaCO}_{3}$ e $\mathrm{MgCO}_{3}$, respectivamente, e o coeficiente de variação de $1,71 \%$. Os tratamentos foram dispostos segundo um delineamento experimental inteiramente casualizado, com oito repetições.

Utilizou-seo arroz (Oryza sativa), cultivar Caiapó, como planta-teste. Cada unidade experimental foi constituída de um vaso com $4 \mathrm{dm}^{3}$ de solo. Durante o cultivo, a umi dade foi control ada, utilizando-se um tensiômetro por vaso, e mantida na faixa de $-7 \mathrm{kPa}$. A água acrescentada a cada unidade experimental correspondeu à perda por evapotranspiração. Colocaram-se também vasos sem plantas para estimar o volume de água evaporada no decorrer do ensaio. O volume de água transpirada foi cal culado por subtração entre o volume total de água perdido por cada unidade experimental e o volume perdido por evaporação. Aos 75 dias da semeadura, as seis plantas de arroz de cada unidade experimental foram col hidas. $\mathrm{O}$ material foi seco a $75^{\circ} \mathrm{C}$ em estufa com ventilação forçada, pesado e moído. Amostras foram submetidas à digestão nitroperclórica, determinando-se o teor de potássio por fotometria de emissão de chama, e o cálcio e o magnésio por espectrofotometria de absorção atômica.

Amostras de solo dos diversos tratamentos, retiradas após a col heita, receberam a quantidade de água necessária para atingir a umidade correspondente a - $7 \mathrm{kPa}$, extraindo-se a solução do solo por centrifugação (Miranda, 1993). Nessas soluções, determinaram-se as concentrações de potássio, cálcio e magnésio. A concentração de cada nutriente na solução do solo multiplicada pelo volume de água transpirado foi usada para estimar a contribuição do fluxo de massa. As quantidades transportadas por difusão foram calculadas, por subtração, entre o nutriente acumulado no vegetal e a quantidade transportada por fluxo de massa.

\section{RESULTADOS E DISCUSSÃO}

No quadro 1, constam as quantidades de matéria seca, de potássio, de cálcio edemagnésio acumuladas nas plantas de arroz. No quadro 2, encontram-se a quantidade de água transpirada e as concentrações deK, Ca eM g na sol ução de solo, cujos valores foram utilizados para cal cular o fluxo de massa. Quando o val or do nutriente acumulado no vegetal foi superior ao do nutriente transportado por fluxo de massa, estimou-se, por diferença, a contribuição da difusão (Figura 1).

Independentemente dosal utilizado, exceto para - $\mathrm{K}_{2} \mathrm{CO}_{3}$, a difusão foi o principal mecanismo de transporte para o potássio, cuja contribuição oscilou entre 89,5 e $94,5 \%$. No caso do $\mathrm{K}_{2} \mathrm{CO}_{3}$, o suprimento de potássio por fluxo de massa foi suficiente para atender à demanda das plantas de arroz em razão da alta concentração de K na solução de solo (Quadro 2).

Apesar de seu baixo teor nos solos das regiões tropicais e úmidas, o cálcio e o magnésio apresentaram disponibilidade suficiente para permitir, por meio do mecanismo defluxo de massa,

Quadro 1. Produção de matéria seca e teores de potássio, de cálcio e de magnésio em plantas de arroz, considerando o sal adi cionado ao solo

\begin{tabular}{ccccc}
\hline \multicolumn{1}{c}{ Sal } & Matéria seca & $\mathbf{K}$ & $\mathbf{C a}$ & $\mathbf{M g}$ \\
\hline & g vaso- & & $\mathrm{mg} \mathrm{g}^{-1}$ & \\
\cline { 3 - 5 } $\mathrm{Na}_{2} \mathrm{CO}_{3}$ & 2,32 & 14,5 & 2,1 & 1,7 \\
$\mathrm{~K}_{2} \mathrm{CO}_{3}$ & 6,07 & 19,6 & 2,4 & 1,6 \\
$\mathrm{CaCO}_{3}$ & 7,65 & 13,4 & 6,0 & 3,2 \\
$\mathrm{MgCO}_{3}$ & 5,19 & 14,6 & 2,1 & 7,5 \\
\hline
\end{tabular}

Quadro 2. Água transpirada pelas plantas de arroz e concentrações de potássio, de cálcio e de magnésio na solução do solo após a colheita do experimento, considerando o sal adicionado ao solo

\begin{tabular}{ccccc}
\hline \multirow{2}{*}{ Sal } & Água transpirada & $\mathbf{K}$ & $\mathbf{C a}$ & $\mathbf{M g}$ \\
\hline & $\mathrm{L}$ vaso-1 & \multicolumn{4}{c}{$\mathrm{mg} \mathrm{L}^{-1}$} \\
\cline { 2 - 5 } $\mathrm{Na}_{2} \mathrm{CO}_{3}$ & 1,040 & 2,4 & 13,0 & 9,8 \\
$\mathrm{~K}_{2} \mathrm{CO}_{3}$ & 1,900 & 1.247 & 19,3 & 20,4 \\
$\mathrm{CaCO}_{3}$ & 3,304 & 1,7 & 725 & 22,5 \\
$\mathrm{MgCO}_{3}$ & 2,439 & 3,3 & 28,0 & 1.237 \\
\hline
\end{tabular}




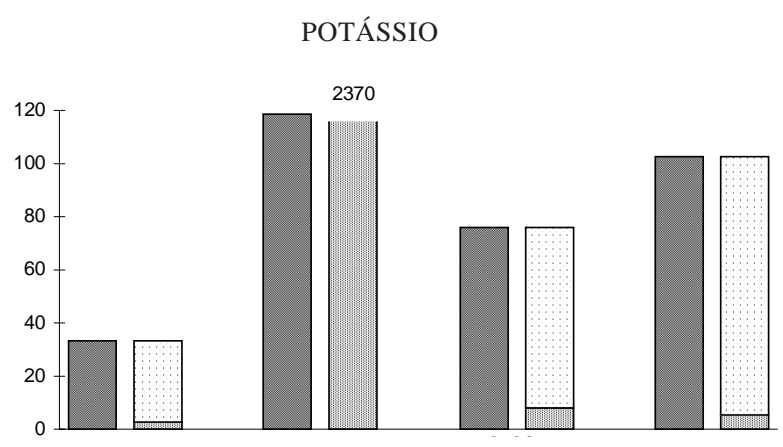

CÁlCIO

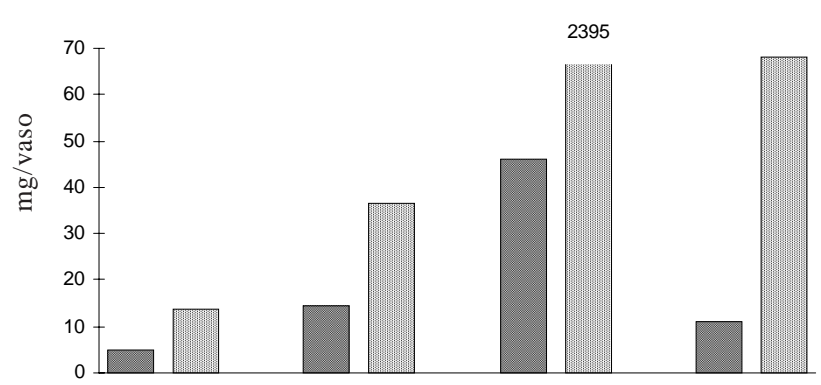

MAGNÉSIO

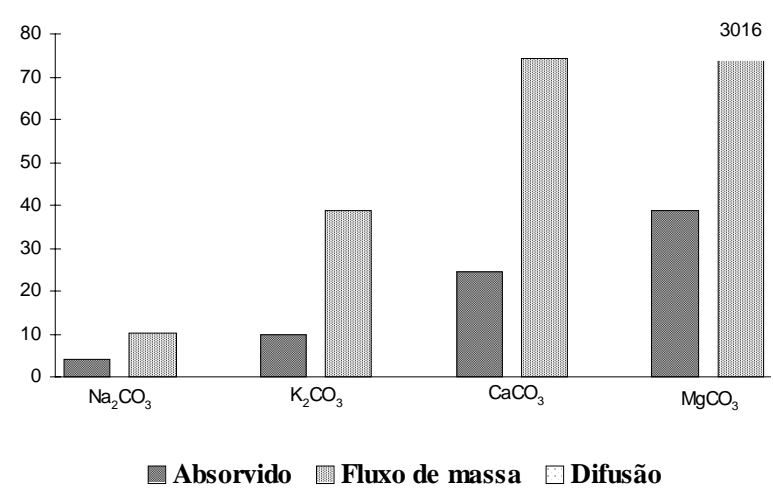

Figura 1. Quantidade de potássio, de cálcio e de magnésio em plantas de arroz e estimativa das quantidades do elemento transportadas por fluxo de massa e por difusão, considerando o sal adicionado ao solo.

que as plantas de arroz fossem adequadamente nutridas. Os valores calculados para fluxo de massa foram consistentemente superiores aos acumulados no vegetal, para todos os tratamentos, oqueconfirma a existência de mecanismos responsáveis pela diminuição da absorção desses nutrientes, quando a demanda da planta foi atendida. O acúmulo de cálcio na superfície radicular foi demonstrado por Barber (1974) por meio de auto-radiografias, em estudos realizados com ${ }^{45} \mathrm{Ca}$.

Como indicado na caracterização do sol o, o cál cio trocável nas amostras utilizadas correspondeu, praticamente, ao triplo daquele do potássio. Por outro lado, a exigência de potássio pelas plantas de arroz correspondeu, aproximadamente, a setevezes aquela do cálcio (Quadro 1, tratamentos com $\mathrm{Na}_{2} \mathrm{CO}_{3}$ e $\left.\mathrm{MgCO}_{3}\right)$. A menor concentração na solução do solo (tratamentos com $\mathrm{Na}_{2} \mathrm{CO}_{3}, \mathrm{CaCO}_{3}$ e $\mathrm{MgCO}_{3}$ ) e a maior exigência da planta impuseram suprimento adicional de potássio, por difusão, em acréscimo ao transportado por fluxo de massa.

Pode-se concluir que a difusão foi o mecanismo de transporte mais importante para K. J á em solo com el evado teor de K na solução, o fluxo de massa proporcionou suprimento adequado de K às plantas. Em todos os tratamentos, o cálcio e o magnésio foram transportados por fluxo de massa em quantidades acima das exigências da planta.

\section{LITE RATURA CITADA}

BARBER, S.A. Influence of the plant root on ion movement in soil. In: CARSON, E.W., ed. The plant root and its environment. Charlottesville, University of Virginia, 1974. p.525-564.

COTTON, F.A. \& WILKINSON, G. Advanced inorganic chemistry. New York, Interscience, 1966. 1136p.

EMPRESA BRASILEIRA DE PESQUISAS AGROPECUÁRIA EMBRAPA. Serviço Nacional de Levantamento e Conservação de Solos. Manual de métodos de análise de solos. Rio de J aneiro, 1979. não paginado.

MIRANDA, J . Caracterização da solução do solo e das propriedades físicas e químicas de um Latossolo Vermel hoAmarelo sob diferentes coberturas vegetais. Viçosa, Universidade Federal de Viçosa, 1993. 65p. (Tese de Mestrado)

RUIZ, H.A. Efeito do conteúdo de água sobre o transporte de fósforo em dois Latossolos. Viçosa, Universidade Federal de Viçosa, 1986. 86p. (Tese de Doutorado)

WILD, A. Mass flow and diffusion. In: GREENLAND, D.J . \& HAYES, M.H.B., eds. The chemistry of soil processes. Chichester, J ohn Wiley, 1981. p.37-80. 